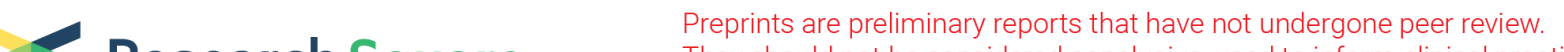 $\begin{array}{ll}\text { Research Square } & \begin{array}{l}\text { They should not be considered conclusive, used to inform clinical practice, } \\ \text { or referenced by the media as validated information. }\end{array}\end{array}$
}

\section{Development of the Houston-Apollo Model for the Older People Living in Remote Areas in Taiwan}

\section{Kai Chieh Chang}

National Taiwan University Hospital Yun Lin Branch

Shou-Hung Hung

National Taiwan University Hospital Yun Lin Branch

\section{Sung-Ju Hsueh}

National Taiwan University Hospital Yun Lin Branch

\section{Shiau-Fang Chao}

National Taiwan University Department of Social Work

Wei-Lieh Huang

National Taiwan University Hospital Yun Lin Branch

Hsin-Shui Chen

National Taiwan University Hospital Yun Lin Branch

Yachung Jeng

National Taiwan University Hospital Yun Lin Branch

Hsiu-Hsi Chen

National Taiwan University Institute of Epidemiology and Preventive Medicine

Horng-Huei Liou ( $\nabla$ hhl@ntu.edu.tw)

National Taiwan University Hospital Yun Lin Branch https://orcid.org/0000-0001-6537-5346

\section{Research article}

Keywords: Telemedicine; community health record; medical equality.

Posted Date: July 2nd, 2020

DOI: https://doi.org/10.21203/rs.3.rs-33918/v1

License: (c) (i) This work is licensed under a Creative Commons Attribution 4.0 International License.

Read Full License

Version of Record: A version of this preprint was published at Geriatrics \& Gerontology International on February 1st, 2021. See the published version at https://doi.org/10.1111/ggi.14130. 


\section{Abstract}

Background: Senior healthcare is challenging in remote areas, especially in an economically disadvantaged population with a high portion of elderly constituents. Guided by Andersen's Behavior Model, this study examined whether a combined health care system (Houston-Apollo Model, HAM) will improve physical performance and foster medical care utilization of the local population.

Methods: People aged $\geq 65$ years who participated in congregate meal services (CMS) were recruited. Using concepts of telemedicine and community health records, participants received consultation from local clinics, which provided advices or arranged referral to National Taiwan University Hospital Yunlin Branch (NTUHYL). Physical parameters including blood pressure, body mass index, grip strength, walking speed, and five-time sit and stand test (FTSST) were recorded and timely transferred to NTUHYL, which in turn result in individualization of intervention strategies. Changes in physical parameters and utilization of healthcare facilities were measured in the beginning of recruitment and one year later to evaluate the effectiveness of the plan.

Results: 470 people were recruited. In 1-year follow-up, the mean systolic and diastolic blood pressure $(\mathrm{mmHg})$ decreased from 137.4 to $133.3(p=0.019)$ and from 76.9 to $74.4(p=0.008)$, respectively. The mean time of FTSST (seconds) decreased from 11.3 to $10.4(p=0.011)$. The mean walking speed $(\mathrm{m} / \mathrm{s})$ increased from 0.71 to $0.74(\mathrm{p}=0.039)$. The rate ratio $(95 \% \mathrm{Cl})$ of medical and dental outpatient clinic usage were 2 (1.1-3.64) and 1.14 (1.06-1.23), respectively.

Conclusions: The HAM health care system could benefit the physical status of older adults, promote proactive and preventive health care utilization, and contribute to medical equality.

\section{Background}

Taiwan has officially become an aged society since 2018 as over 14 percent of its population is 65 years old or above. The National Development Council projected that Taiwan will be a super-aged nation by 2026. Taiwan has the fastest increasing rate of the aged population compared with other countries of the world. Yunlin County is the second oldest county in Taiwan. Despite having more aged people in this agricultural county, seeking health services is a daunting task for them. Unfortunately, insufficient health and transportation services in the rural and remote areas have created barriers for these old people to seek medical help [1-3]. To bring down the barriers, telemedicine could be an effective approach [4], given that the broadband access had reached $96.7 \%$ coverage in rural and remote areas of Taiwan by 2017 [5]. Hence, to initiate a program that can integrate telemedicine to overcome the barriers of limited access to medical resources is timely and necessary.

To meet the nutritional needs of older people and offer opportunities for social engagement, Yunlin County Government provided social welfare system in setting congregate meal services (CMS) in every township. Local organizers offered meal for nearby persons 65 years and older. Half of the cost (30 NTD/meal, which equals around 1 US dollar) was paid by the diners, and another half was paid by the 
government. For seniors from low income families, the government subsidized them to have free congregate meal program. With the program, the older people could regularly have nutritious meals with the affordable price. They were motivated to go out from their home by cheaper meals. The organizers also provide gathering places for the participants, which serve as a platform to improve interpersonal relationship and socialization. The CMS in Yunlin County was popular among senior citizens. There were approximately $120 \mathrm{CMS}$ for senior citizens. One senior dining hall would serve 30 to 150 (with an average of 50) older people, and around 10,000 older people received this service regularly. Government provided the welfare service with cost of 60 to 70 million NTD (around 2 million USD) per year.

Research literature has demonstrated that participation in CMS can enhance daily nutrient intake, nutritious status, the amount of social interactions, and functionality of older adults [6]. Prior to this project, the CMS did not take health improvement as a major goal. An evidence-based model of health care in such community service was also lacking. The purpose of this project is to describe a geriatric health service model to integrate CMS, primary care doctors, and hospital. We aimed to make efforts in promoting proactive and preventive care in order to improve geriatric health outcomes in remote areas.

\section{Houston-Apollo-Model}

To establish the integration, National Taiwan University Hospital Yunlin Branch (NTUHYL) has initiated a project with telemedicine since November 2018. Inspired by Project Apollo of National Aeronautics and Space Administration that has modeled a magnificent teamwork in which mission control center in Houston guided the crew of Apollo-13 to successfully complete their missions and brought the astronauts home safely, we named this project Houston-Apollo-Model (HAM). With this project, NTUHYL, worked as Houston's mission control center to guide and support primary care physicians (as the crew of the Apollo spacecraft), who provided free health consultation in rural and remote villages or townships via telemedicine. If there were difficulties in dealing with the health problems of the old people, the local primary care physicians could call for help in NTUHYL. Healthcare professionals in NTUHYL would then tackle the problem that the primary care physician encountered in practice. We collaborated as a team to deliver health care services that rural old population needs.

\section{Local primary care doctors}

To build the collaboration, NTUHYL first invited local primary care doctors practicing in rural and remote communities to participate in HAM. They were eligible to join the project if they were willing to spend 60 minutes a day, five days a week, using video-conference to provide free health consultation to the old people in the CMS. Primary care doctors were chosen if their clinics are located within 10 minutes' drive from the CMS. The doctors who were willing to join the project were interviewed by NTUHYL and provided with information about the project. NTUHYL provided video-conferencing devices and equipments for every primary care setting and CMS to deliver telemedicine consultation services and health education. Each doctor served 1 to 2 CMS at noon, when the old people would gather and wait for their lunch.

\section{Settings in CMS}


We used technology devices, nicknamed Baby Machine, to measure and monitor the vital signs and physical parameters. Measurement of vital signs included height, weight, and blood pressure. Physical parameters included body mass index (BMI), grip strength, five-time-sit-to-stand test (FTSST), and 6 metered walking speeds.

The older people, local doctors, and NTUHYL formed a bidirectional triangle (Fig. 1). The older people received consultation from local doctors if they had (1) sickness or medical problems, (2) abnormal vital sign measured from the Baby Machine, (3) potential of polypharmacy misuse. In response to the consultation, the local doctors had following strategies: (1) providing advices directly, (2) asking the older people to visit their clinic if medication is needed, (3) consulting doctors in NTUHYL if medical specialty needed, (4) arranging transferal to NTUHYL. In addition, physical status of the old people was timely transferred to NTUHYL, which would then generate intervention strategies, for example, cooking guidance to the service meal providers, physical training therapeutics dispatched from the hospital. In the opposite direction, health education and policies from governments would be promoted from NTUHYL and local doctors to the older people to overcome information insufficiency in rural areas. In addition to provide the necessary health information, the physical therapeutics performed health exercise trainings and introduced new health exercise devices. At the time of writing this manuscript, there were $12 \mathrm{CMS}$ and 8 local primary care doctors joined the project.

A 1-year community-based research comparing pre-intervention and post-intervention was performed to exam the effectiveness of HAM. Before launching the project, we provided training courses about how to use telemedicine devices and Baby Machine to the long-term care staff members working at every CMS. The data collected from the devices were then sent to the data center at NTUHYL for storage and analysis.

\section{Guiding Framework and Research Hypotheses: Anderson's Behavior Model}

This study concerns the extent to which the physical performance and health service utilization of older adults who reside in a rural area are affected by the HAM and its interactive effect with the CMS. To demonstrate the possible processes that change the physical performance and health service utilization behaviors of research participants, and the mechanisms that potentially underlie these processes, the Behavioral Model of Health Services Utilization that was proposed by Andersen \& Newman adopted as a theoretical framework (Fig. 2) [7]. The original Behavior Model that was developed in 1960s explains individual health service use behaviors as a function of predisposing (demographic and social) factors, enabling (personal, family and community barriers to, and facilitators of service use) factors, and needs (potential needs for health services) [8]. While the original model focuses on individual characteristics, the revised model of 2005 emphasizes the role of societal determinants, such as technology, in facilitating the delivery of services by health care organizations, in influencing individual determinants of health care utilization, and in changing an individual's actual usage behavior. Motivated by the model of Andersen \& Newman, the following two hypotheses are proposed. First (hypothesis 1 in Fig. 2), the development of 
HAM facilitates accessibility to medical care services in Yunlin county, compensating for inadequate medical care in this rural area, enhancing community enabling factors, and improving the physical performance of older adults. Second (hypothesis 2 in Fig. 2), a combination of a technology-assisted community outreach project (HAM), accessible health service systems, and enhanced community enabling factors (CMS) helps older adults to overcome barriers to medical care utilization and reduces medical inequities in a resource-remote area by increasing the usage of proactive and preventive care by older individuals. This increase in usage includes increases in the total number of visits to dentist and outpatient clinics but not to hospitals or emergency rooms.

\section{Methods}

\section{Subjects}

We recruited people aged $\geq 65$ years in the $12 \mathrm{CMS}$. The participants were offered both written and verbal explanations of the study before we obtained formal consents from them. They were also assured the confidentiality of their information.

\section{Measures and Data collection}

Demographic data were collected in the beginning of the intervention, including age, sex, and underlying chronic diseases. The vital signs (height, weight, and blood pressure) and frailty parameters (BMI, grip strength, FTSST, and 6 metered walking speeds) were collected monthly under direction of staff members in the service. Only subjects who had Baby machine-measured data at beginning of and one year after the Project were used for longitudinal comparison (Fig. 2). Further, these data were also compared to previous study in one rural county (Hualian) and urban county (Taichung) of Taiwan [9], and another urban area in Asia region (Hong Kong) [10].

Hypertension was determined according to 2018 guideline of American Heart Association (AHA) [11]. Hypertension stage 1 was defined by systolic $B P \geq 130 \mathrm{mmHg}$ or diastolic $B P \geq 80 \mathrm{mmHg}$, and stage 2 was systolic $B P \geq 140 \mathrm{mmHg}$ or diastolic $\mathrm{BP} \geq 90 \mathrm{mmHg}$. BMI was determined according to the World Health Organization [12]. BMI $<18.5$ was defined as underweight. BMI 18.5 to 24.9 was defined as normal weight. BMI 25.0 to 29.9 was defined as pre-obesity. BMI $\geq 30$ was defined as obesity. For screening physical function, a cut-off point of $0.68 \mathrm{~m} / \mathrm{s}$ in walking speed, $30.5 \mathrm{~kg}$ in grip strength for men, and $0.66 \mathrm{~m} / \mathrm{s}$ and $21.5 \mathrm{~kg}$ for women were used [9]. For FTSST, the score was assigned from 1 (the slowest) to 4 (the fastest). The length of time required for the measure was used for scoring, with a score of 1 representing $\geqq 16.7$ seconds; a score of 2 representing 13.7 to 16.6 seconds; a score of 3 representing 11.2 to 13.6 seconds; a score of 4 representing $\leqq 11.1$ seconds [13]. The staff at each CMS helped the older people to correctly use the telemedicine devices and guide them to perform various physical activities for measuring their physical function.

Hospital utilization was also calculated to evaluate change in medical accessibility and equality. The medical resource access toward the NTUHYL in 2018 and 2019 of the 470 participants were 
retrospectively retrieved via electronic medical record system. The access records were classified into four categories: dental outpatient visiting, outpatient visiting to other departments, hospitalization, and emergency department visiting.

\section{Statistical Analysis}

Demographic data were summed by descriptive analysis. Continuous variables were expressed with means and their standard deviation (SD). Categorical variables were expressed with numbers and percentage (\%). In comparison with previous studies, $t$-test was used to compare specific summary statistics $[9,10]$. McNemar's test was used to test whether or not disease status was consistent across the two sampling time in grip strength and walking speed. Chi-square test was used to compare change in hypertension and FTSST due to multiple groups of disease status. The medical resource utilization was evaluated using the access frequency of dental outpatients, outpatients for other departments, hospitalization, and emergency department. The individual access frequency of the four categories were analyzed in a marginal Poisson regression model, wherein a dichotomous variable indicated access year (2018 or 2019). The results were summarized in the number of users $(\mathrm{N})$, and amounts of access frequency (PT), the individual medical use rate (R), and the rates ratio (RR) of 2019 to 2018 . The associated $95 \%$ confidence interval $(\mathrm{Cl})$ and a Wald test $\mathrm{p}$-value were estimated under the Poisson model. The analyses were performed by Stata/SE 8.0.

\section{Results}

There were 8 primary care doctors and 727 older people who had registered in the 12 CMS (Fig. 2). 244 people did not actually have lunch in the CMS and received home meal services due to ambulation disability or work. 470 of the rest 483 people agreed to join the project under inform consent. These included 187 men and 283 women (Table 1). The mean (SD) age was 75.55 (6.5) years. The parameters were measured at the beginning of the Project. $65.95 \%$ had hypertension according to AHA. 98 (24.75\%) belonged to hypertension stage 1 and $192(48.48 \%)$ belonged to stage 2.14 (3.84\%) were underweight, 107 (29.32\%) were overweight, and 22 (6.03\%) were obese. 209 (50.36\%) had weakness in grip strength. In FTSST, $71(16.82 \%)$ had worst performance (score $=1)$; $82(19.43 \%)$ had score $=2$; $92(21.8 \%)$ had score $=3$; and the rest $177(41.94 \%)$ had best performance $($ score $=4) .307(77.92 \%)$ had disability in walking speed.

As compared with the cohorts in Taichung (represents an urban area) and Hualien (represents a rural area) in Taiwan and Hong Kong (Supplement Table 1), the pre-intervention physical parameters of the older people in Yunlin County had significantly weaker grip strength $(\mathrm{kg})$ (mean (SD) = $21.35(8.29)$ ) to Taichung (25.6 (8.5), $p<0.001)$, Hualien (27.6 (7.8), $p<0.001$ ), and Hong Kong (25.7 (7.7), $p<0.001$ ), slower FTSST (seconds) (mean (SD) $=12.75(4.83)$ ) to Taichung (10.6 (5), $p<0.001)$ and Hualien $(10.2$ (3.2), $\mathrm{p}<0.001)$, and slower walking speed $(\mathrm{m} / \mathrm{s})$ (mean $(\mathrm{SD})=0.85(2.52))$ to Hualien $(1.24(0.27), \mathrm{p}<$ $0.001)$. 
In response to the first research hypothesis, of the 97 participants who had repeated hypertension evaluation one year after the beginning of the project (Table 2), the mean systolic and diastolic blood pressure $(\mathrm{mmHg})$ decreased from $137.4(20.1)$ to $133.3(19.6)(p=0.019)$ and from 76.9 (12.9) to 74.4 (12.5) $(p=0.008)$, respectively. However, the numbers of AHA disease status were exactly the same (normal: 30 , hypertension stage $1: 26$, hypertension stage $2: 41)$. The mean grip strength $(\mathrm{kgw})$ of 88 older people was 22.3 (8.42) and 23.0 (7.39) before and after the intervention ( $p=0.107)$, respectively. There was no significant change in numbers of disability ( 56 to $54, p=0.593$ ). Of 96 people who received repeated FTSST, the mean exercise time (seconds) decreased from $11.3(3.92)$ to $10.4(3.08)(p=0.011)$. There was no significant change in score groups $(p=0.125)$. The mean walking speed $(\mathrm{m} / \mathrm{s})$ of 81 people who received repeated evaluation increased from $0.71(0.25)$ to $0.74(0.23)$, but there was also no significant change in numbers of disability ( 37 to $31, p=0.109$ ).

As for the second research hypothesis, the evaluation results on the medical resource utilization before and after the project launched were summarized in Table 3. Both the outpatients visiting to dental and other departments were increased significantly, suggesting that the second research hypothesis was supported. The changes in the user numbers of dental and other departments increased respectively from 6 and 162 to 8 and 184. These in the amounts of access frequencies were that 16 increased to 32 and 1193 increased to 1362 . This resulted in rate increasing: 0.03 to 0.07 and 2.54 to 2.9 (rate ratio $[95 \% \mathrm{Cl}]=$ 2 [1.1-3.64] and 1.14 [1.06-1.23]), which corresponded to $100 \%$ and $14.2 \%$ increasing. In contrast, the user number (46 and 45 in 2018 and 2019 respectively), use amounts (66 and 53), and annual use rate ( 0.14 and 0.11 ) of emergency room access were all declined in 2019 even though the rate ratio $(0.8$ [0.56-1.15] for a declining of 19.7\%) did not achieve a statistical significance. For hospitalization, the use pattern is relatively stable: reducing slightly and non-significantly merely in use amounts (for a $3 \%$ reduction). Four cases had new diagnosed cancer (acute myeloblastic leukemia, malignant neoplasm of bladder, malignant neoplasm of sigmoid colon, and malignant neoplasm of cecum, respectively) found by the referral system of HAM.

\section{Discussion}

This study is innovative in adopting Andersen's Behavior Model of Health Services Utilization to explore how HAM integrated government social welfare service, and local primary care doctors with medical center to deliver telemedicine services, measured, and tracked vital signs and physical parameters to promote proactive and preventive care for them in remote areas. When older people noticed physical discomfort, they could access free and convenient health consultation form general physician, and receive referral to the primary care doctor or hospital for further care if needed. Baby Machine, on the other hand, provided active registration of abnormal physical findings, which incorporated into NTUHYL database, which could later inform the older people and staffs of CMS to seek for health consultation. Our results detected high prevalence of hypertension, obesity, and poor physical performance of older people in CMS. When they alerted this situation, they gained awareness of health issues. There were improvements in physical parameters including mean blood pressure, FTSST and walking speed. 
Although the National Health Insurance of Taiwan has lowered the financial burden of medical cost, the geographically uneven distribution of medical facilities caused inequality of medical accessibility, especially in rural areas. The increased usage of outpatient clinics and dentists, and early detection of cancers suggests that by educating health knowledge for the old people, HAM compensated the deficiency of transport and knowledge aspects in rural areas.

\section{Telemedicine-based Intervention}

Our model demonstrated a new method for community intervention, which improved health of old people in rural areas in a simple but persistent manner. The common intervention in preventing frailty of older people usually included physical trainings [14-17], nutrition assessment $[14,15,18]$, which was performed by dispatched therapist within limited time period. Although this kind of intervention usually provide good effectiveness, the cost-effectiveness regarding cost of medical services was either not taken into account [19] or showed greater cost [20,21]. In HAM, we used telemedicine to reduce the distance barrier between the rural older people and health care providers, thus decreased the cost and provided a sustainable system without time restriction. This advantage gives us a chance for long term follow-up.

Telemedicine was proved to be effective to improve health care in rural area [22]. In systemic review, most intervention was delivered by students, psychologists, and nurses, while doctors were involved only in $19 \%$ of studies, and usually as a provision role [22]. However, doctors have indispensable role in managing multi-disciplinary care for chronic diseases of old people and protect them from unnecessary burden of care [23]. The difficulty to incorporate local primary care physician is the major limitation in performing telemedicine. Doctors usually had reluctance with concerns regarding financial and legal aspects that constitute obstacles to the development of telemedicine [24]. Moreover, personal data protection is also an important issue [24]. In HAM, the primary doctors served as consulting counters and provided general health suggestions without receiving direct payment from the CMS. Instead, the doctors would consolidate their role of major health care provider in a local area and build up belongingness of the country. Furthermore, the doctors would receive back support of specialist in NTUHYL if there were medical problems beyond the capacity of local clinics. NTUHYL also help primary doctors setting telecommunication system with the standard of electronic medical record protection, which provided a safe platform of telemedicine.

\section{Community Health Records}

The continuous record of health parameters in HAM provided personalized health record of the participants. Moreover, it showed the potential benefits of the shared resources in terms of medical research and policy formation. The concept of community health records provided a more complete view of population health, targeting community health interventions in a data-driven manner [25]. Incorporation of electronic health records could dramatically increase the timeliness of data availability [26]. This collaboration can not only compensate the shortage access to medical care in rural areas but also help gather data to improve the quality or focus of healthcare in those areas. To manage the physical disability found in HAM, NTUHYL has launched several ongoing projects targeting nutrition, 
dental condition, cognitive and psychiatric status, and osteoporosis in the CMS. For example, the recipe of CMS was adjusted by hospital dietician based on the function status and original diet habits. Multidiscipline health screen focusing on physical disability was also performed in a single communitytailored strategy. The effectiveness of these interventions could be monitored by HAM with high efficiency.

\section{Limitation}

The high drop-out rate of continuous monitor is a major limitation. The reduced sample number may also explain lack of significance of change in disease status, in contrast to the significant change in physical parameters. The decline of motivation of the participants is the main reason. To improve compliance, we applied several methods such timely recommendation of the monitored abnormalities to improve participants' belief of usefulness of health monitoring and system of rewarding point collection for daily necessities. The measured data also lack of strict quality control. However, all staff members in CMS have received adequate training to reduce the inter-rater variability. The possible benefits of HAM were demonstrated by change in medical resource utility. Longer effectiveness should be proved by change in disease incidence and mortality.

\section{Conclusion}

HAM manifests a model of integrating medical resources for the benefits of the deprived and the needed to counteract the unbalanced distribution of medical resources. It has been known that organizing and coordinating resources across different levels and sites of healthcare is far more complex than maintaining the existing health care system. This model can provide an example of an effective way to consolidate limited resources and achieve a more than satisfactory outcome.

\section{List Of Abbreviations}

AHA: American Heart Association, BMI: body mass index, CMS: congregate meal services, FTSST: fivetime-sit-to-stand test, HAM: Houston-Apollo model, NTUHYL: National Taiwan University Hospital Yunlin Branch.

\section{Declarations}

Ethics approval and consent to participate: This project had received Research Ethics Committee approval from National Taiwan University Hospital (201812199RIND). The participants were offered both written and verbal explanations of the study before we obtained formal written consents from them.

Consent for publication: Not applicable.

Availability of data and material: The datasets generated during and/or analyzed during the current study are not publicly available due ethical restrictions but are available from the corresponding author on 
reasonable request.

Competing interests: The authors had no conflicts of interest to report.

Funding: National Taiwan University Hospital Yunlin Branch supported HAM as a research funding (NTUHYL109.A004), but did not determine the design of the study and collection, analysis, and interpretation of data and in writing the manuscript.

Authors' contributions: HHL planed the study, analyzed the data, and wrote the article. KCC collected subjects and data, analyzed the data, and wrote the article. SHH collected subjects and data. SJH wrote the article. WLH collected subjects and data. HSC collected subjects and data. YJ performed statistical analyses. HHC planed the study.

Acknowledgements: We are grateful to the older adults and doctors of local clinics who participated this project. All authors read and approved the finalversion of the manuscript.

\section{References}

1. Ricketts TC. Workforce issues in rural areas: a focus on policy equity. American journal of public health. 2005;95(1):42-8.

2. Douthit N, Kiv S, Dwolatzky T, Biswas S. Exposing some important barriers to health care access in the rural USA. Public Health. 2015;129(6):611-20.

3. Nawal Lutfiyya M, Bhat DK, Gandhi SR, Nguyen C, Weidenbacher-Hoper VL, Lipsky MS. A comparison of quality of care indicators in urban acute care hospitals and rural critical access hospitals in the United States. International journal for quality in health care: journal of the International Society for Quality in Health Care. 2007;19(3):141-9.

4. Batsis JA, DiMilia PR, Seo LM, Fortuna KL, Kennedy MA, Blunt HB, Bagley PJ, Brooks J, Brooks E, Kim SY, et al. Effectiveness of Ambulatory Telemedicine Care in Older Adults: A Systematic Review. J Am Geriatr Soc. 2019;67(8):1737-49.

5. News release [https://www.ncc.gov.tw/chinese/news_detail.aspx?site_content_sn=8\&sn_f $=40542]$.

6. Thomas L Jr, Almanza B, Ghiselli R. Nutrition knowledge of rural older populations: can congregate meal site participants manage their own diets? J Nutr Elder. 2010;29(3):325-44.

7. Andersen R, Newman JF. Societal and Individual Determinants of Medical Care Utilization in the United States. Milbank Q 2005, 83(4):10.1111/j.1468-0009.2005.00428.x.

8. Andersen RM. National health surveys and the behavioral model of health services use. Medical care. 2008;46(7):647-53.

\section{Lin YH: The Cutoff Values of Performance Tests to Separate Community-Dwelling Older Adults with} and without Physical Disability. Taiwan Geriatrics \& Gerontology 2012, 2012.08(7:3):160-174.

10. Auyeung TW, Lee JS, Leung J, Kwok T, Woo J. The selection of a screening test for frailty identification in community-dwelling older adults. J Nutr Health Aging. 2014;18(2):199-203. 
11. Whelton PK, Carey RM, Aronow WS, Casey DE Jr, Collins KJ, Dennison Himmelfarb C, DePalma SM, Gidding S, Jamerson KA, Jones DW, et al: 2017 ACC/AHA/AAPA/ABC/ACPM/AGS/APhA/ASH/ASPC/NMA/PCNA Guideline for the Prevention, Detection, Evaluation, and Management of High Blood Pressure in Adults: A Report of the American College of Cardiology/American Heart Association Task Force on Clinical Practice Guidelines. Hypertension (Dallas, Tex: 1979) 2018, 71(6):e13-e115.

12. Organization WH: Obesity: preventing and managing the global epidemic: World Health Organization; 2000.

13. Guralnik JM, Ferrucci L, Pieper CF, Leveille SG, Markides KS, Ostir GV, Studenski S, Berkman LF, Wallace RB. Lower extremity function and subsequent disability: consistency across studies, predictive models, and value of gait speed alone compared with the short physical performance battery. The journals of gerontology Series A Biological sciences medical sciences. 2000;55(4):M221-31.

14. Chan DC, Tsou HH, Yang RS, Tsauo JY, Chen CY, Hsiung CA, Kuo KN. A pilot randomized controlled trial to improve geriatric frailty. BMC Geriatr. 2012;12:58.

15. Ng TP, Feng L, Nyunt MS, Feng L, Niti M, Tan BY, Chan G, Khoo SA, Chan SM, Yap P, et al. Nutritional, Physical, Cognitive, and Combination Interventions and Frailty Reversal Among Older Adults: A Randomized Controlled Trial. Am J Med. 2015;128(11):1225-36.e1221.

16. Binder EF, Schechtman KB, Ehsani AA, Steger-May K, Brown M, Sinacore DR, Yarasheski KE, Holloszy JO. Effects of exercise training on frailty in community-dwelling older adults: results of a randomized, controlled trial. J Am Geriatr Soc. 2002;50(12):1921-8.

17. El-Khoury F, Cassou B, Latouche A, Aegerter P, Charles MA, Dargent-Molina P. Effectiveness of two year balance training programme on prevention of fall induced injuries in at risk women aged 75-85 living in community: Ossébo randomised controlled trial. BMJ. 2015;351:h3830.

18. Serra-Prat M, Sist X, Domenich R, Jurado L, Saiz A, Roces A, Palomera E, Tarradelles M, Papiol M. Effectiveness of an intervention to prevent frailty in pre-frail community-dwelling older people consulting in primary care: a randomised controlled trial. Age Ageing. 2017;46(3):401-7.

19. Haji Ali Afzali H, Karnon J, Theou O, Beilby J, Cesari M, Visvanathan R. Structuring a conceptual model for cost-effectiveness analysis of frailty interventions. PloS one. 2019;14(9):e0222049.

20. Fairhall N, Sherrington C, Kurrle SE, Lord SR, Lockwood K, Howard K, Hayes A, Monaghan N, Langron $\mathrm{C}$, Aggar $\mathrm{C}$, et al. Economic evaluation of a multifactorial, interdisciplinary intervention versus usual care to reduce frailty in frail older people. J Am Med Dir Assoc. 2015;16(1):41-8.

21. Suijker JJ, MacNeil-Vroomen JL, van Rijn M, Buurman BM, de Rooij SE, Moll van Charante EP, Bosmans JE. Cost-effectiveness of nurse-led multifactorial care to prevent or postpone new disabilities in community-living older people: Results of a cluster randomized trial. PloS one. 2017;12(4):e0175272.

22. Speyer R, Denman D, Wilkes-Gillan S, Chen YW, Bogaardt H, Kim JH, Heckathorn DE, Cordier R. Effects of telehealth by allied health professionals and nurses in rural and remote areas: A 
systematic review and meta-analysis. J Rehabil Med. 2018;50(3):225-35.

23. Lam CL. The role of the family doctor in the era of multi-disciplinary primary care. Family practice. 2016;33(5):447-8.

24. Durupt M, Bouchy O, Christophe S, Kivits J, Boivin JM: [Telemedicine in rural areas: general practitioners' representations and experiences]. Sante publique (Vandoeuvre-les-Nancy, France) 2016, 28(4):487-497.

25. Van Brunt D. Community Health Records: Establishing a Systematic Approach to Improving Social and Physical Determinants of Health. American journal of public health. 2017;107(3):407-12.

26. Hatef E, Weiner JP, Kharrazi H. A public health perspective on using electronic health records to address social determinants of health: The potential for a national system of local community health records in the United States. International journal of medical informatics. 2019;124:86-9.

\section{Tables}

Tables 1-3 and Supplemental Table 1, as cited in the Results section, are not included with this version.

\section{Figures}

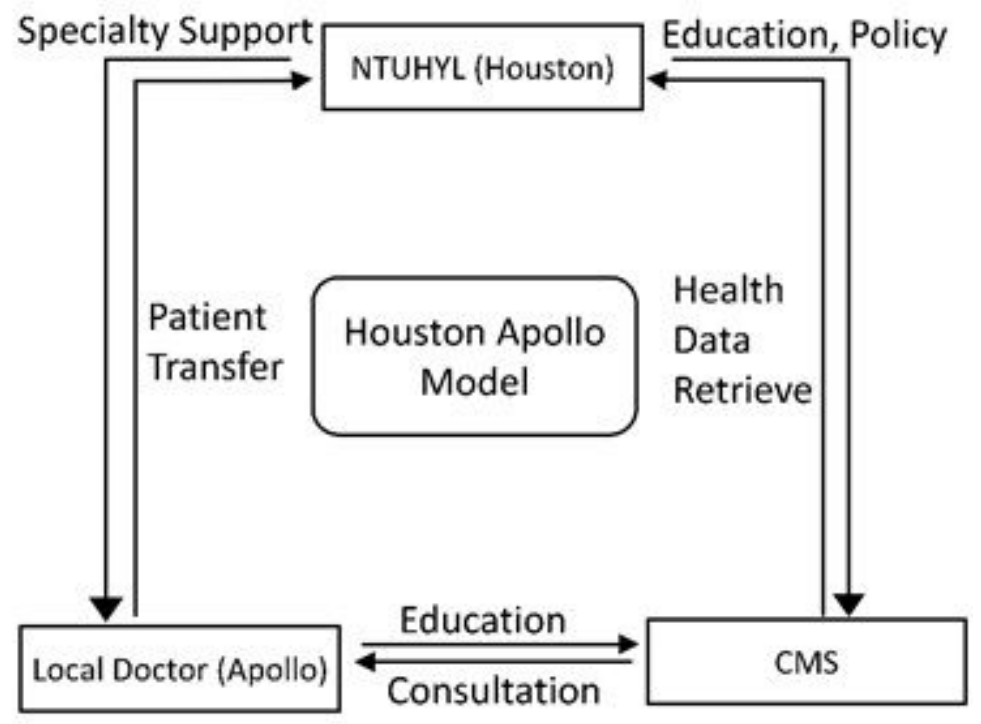

\section{Figure 1}

The schematic diagram of the members and cooperation connection in HAM. NTUHYL, local doctors, and CMS formed a bidirectional triangle. Older people in the CMS had regular interaction of their health issue with local doctors. If specialty is needed, local doctors may seek help from NTUHYL. NTUHYL also received monitoring data from $\mathrm{CMS}$, and provided education and health policy propagation to CMS. CMS: Congregate meal services; NTUHYL: National Taiwan University Hospital Yunlin Branch 


\section{Societal Determinants}

\section{Health Services System}

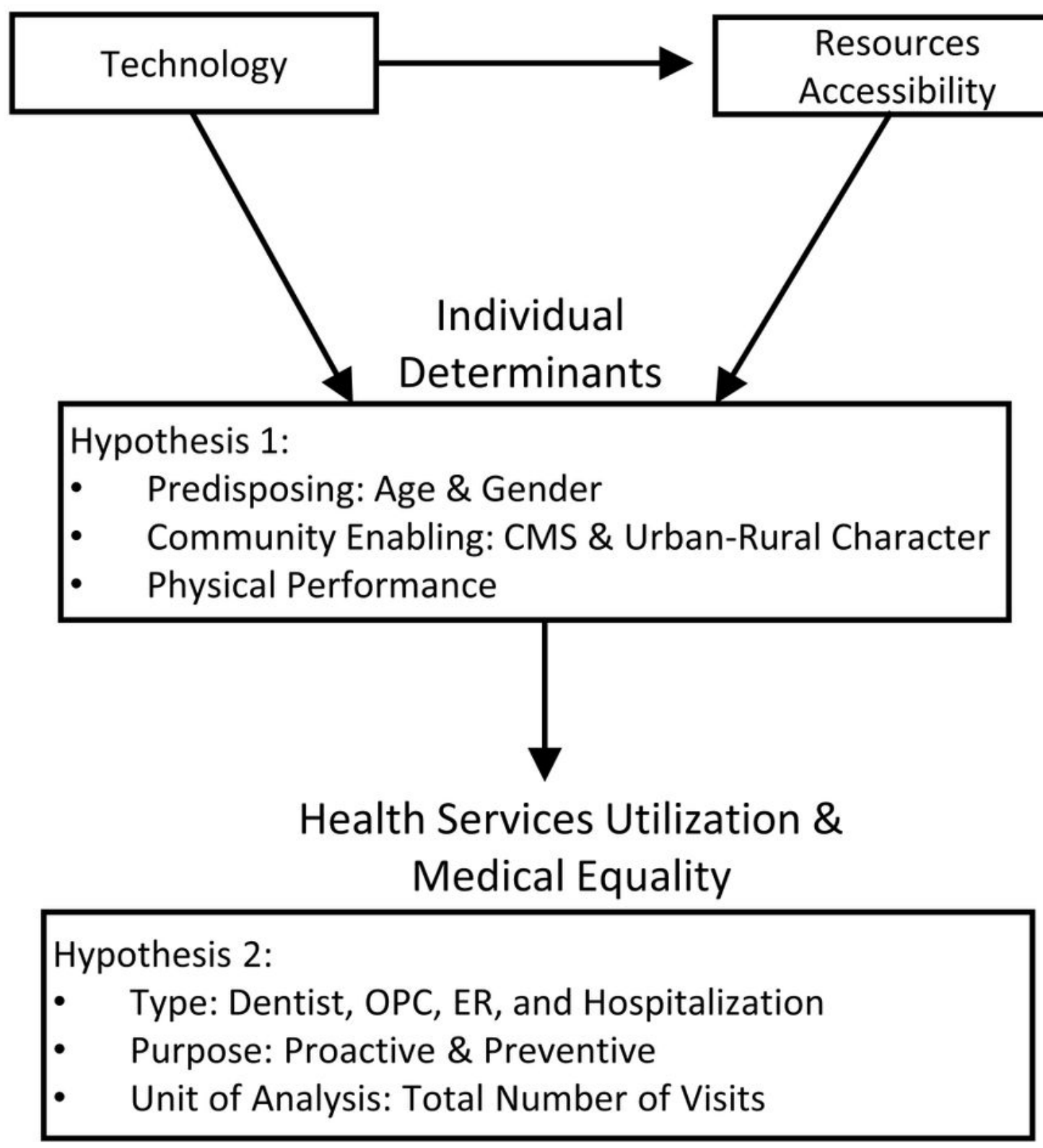

Figure 2

Guiding Framework and Research Hypotheses modified from Andersen's behavior model. Guiding by Andersen's behavior model, Houston-Apollo Model used technology with telemedicine and health services system of CMS to reform individual determinants (hypothesis 1) and to alter medical behavior (hypothesis 2). CMS: Congregate meal services, ER: Emergency room service, OPC: Outpatient clinic. 


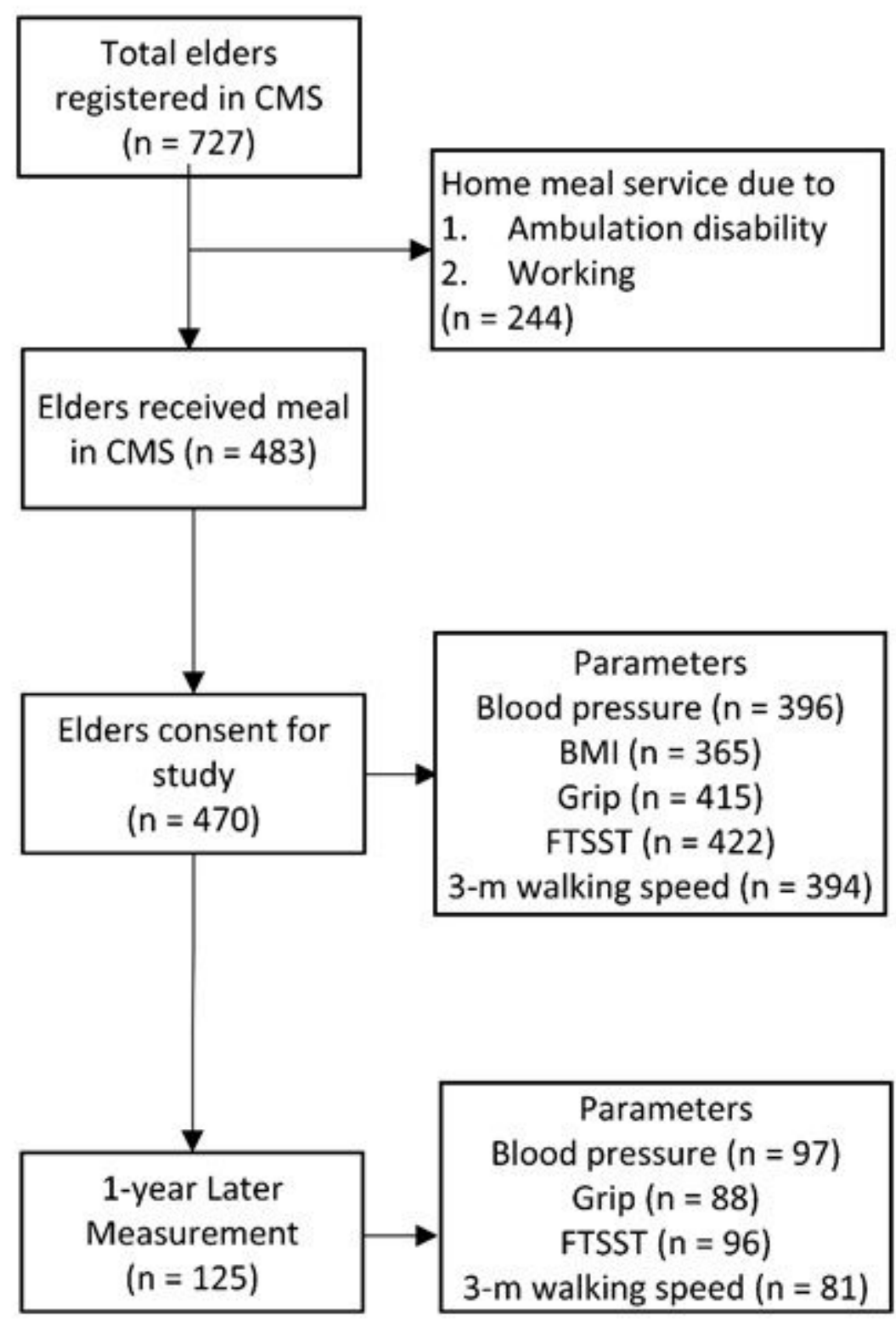

Figure 3

Recruitment Process Flowchart. BMI: body mass index; CMS: Congregate meal services; FTSST: five-timesit-to-stand test. 